\title{
Simultaneous Identification and Determination of Three Different Classes of Pesticides in Tehran Drinking Water by HPLC/UV Technique
}

\author{
Mahtab Baghban, Alireza Rezaian, Elaheh Hashemi* \\ Tehran Province Water and Wastewater Research Group, Tehran, Iran \\ * Corresponding author E-mail address: ellhashemi@yahoo.com, Tel.: +982181752875, \\ Fax: +982188973072
}

Received: 17 October 2018, Revised: 29 October 2018, Accepted: 18 November 2018

\begin{abstract}
A B S T R A C T
An efficient sample extraction using solid-phase extraction coupled with liquidchromatography was studied for the analyses of three different types and chemical group pesticides from drinking water. The extraction was performed using a Waters Sep-Pak C-18 cartridge. A validation of the method was performed. Linearity $(0.005-1000,0.01-1000,4-$ $1000,10.5-1000$ and 9.48-1000 $\mu \mathrm{g} . \mathrm{L}^{-1}$ for Simazine, Atrazine, Isoproturon, Metolachlor and Chlorotoluron respectively range), within-day precisions ranged from 4.8 to $6.7 \%$ and the between day precisions ranged of 7.8-13.3 \% based on the peak areas for five replicates, limits of detection (0.001-2.846 $\left.\mu \mathrm{g} . \mathrm{L}^{-1}\right)$ were calculated. The preconcentration factors (PFs) were obtained under the optimum conditions (15.04-22.53). The information obtained from the method validation has been used to estimate for the determination of pesticides at trace levels in water samples which collected from water treatment plants of Tehran, the capital of Iran.
\end{abstract}

Keywords: Solid Phase Extraction (SPE), Pesticides, HPLC, Drinking Water.

G R A P H I C A L A B S T R A C T

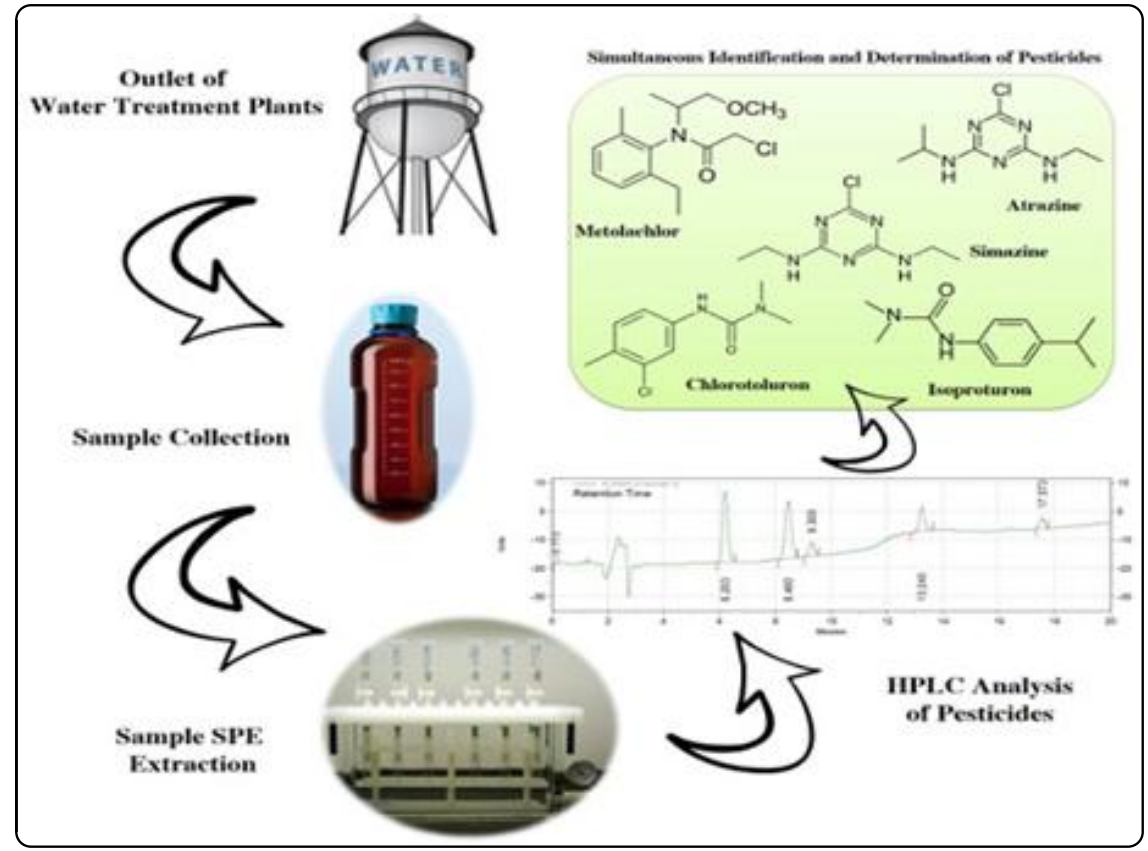




\section{Introduction}

Although access to safe and consistent drinking water is imperative for a healthy population, surface water may be contaminated with pesticides byagricultural, household and industrial application [1]. Pesticides from different chemical classes are frequently used for the switch of pests in several crops and are persistent organic pollutants. Organochlorine pesticides which used as insecticides, herbicides, fungicides, rodenticides and Organophosphorus pesticides such as carbamates, pyrethroids and neonicotinoids are common classes of pesticides which are widely used in the world for pest control. Therefore, the occurrence of pesticide residues is available in the aquatic environment and drinking water and can have adverse effects on humans and other nontarget species [2-4]. Since the relationship between application rates and concentration of pesticides in water is multipart and varies significantly over space and time, analysis and intensive long-term monitoring are essential [5]. The contamination of surface and ground water by pesticides is discussed by different authors [6-8] with sensitive methods due to the low levels detected in the samples such as gas chromatography (GC) with electron capture detection (ECD) [9], flame photometric detection [10], nitrogen- phosphorus detection (NPD) [11], liquid chromatography (LC) with fluorescence detection [12] and diode-array detection [13], and especially mass spectrometry (MS) detectors for both techniques [14, 15]. Therefore, HPLC is a good alternative technique which isocratic or gradient elution can separate the mixing compounds. In addition, monitoring the pesticide concentrations is especially important in drinking water. Drinking water samples can be collected, dechlorinated, preserved, shipped and stored as described by the EPA methods 532 or 535 . As it is clear in this standard methods, the monitoring methodology of pesticides in water has mainly focused on a single pesticide type or substance group with similar physicochemical properties. So, developments of new approach based on GC or LC methods for fast and simultaneous determination of different types of pesticides are attractive.

On the other hands, the environmental samples are too diluted or complex in which, prior to the analysis, a sample preconcentration and purification are performed to extract trace amounts of pesticides from the aqueous medium and bring the analytes to a suitable concentration level by removing them from interfering components in the matrix [16]. Typically, solid phase extraction (SPE) is the 
most commonly used one to extract multiresidue compounds [9].

In this work, Simazine (Triazine class), Atrazine (Triazine class), Chlorotoluron (Phenylurea class), Isoproturon (Phenylurea class) and Metolachlor (Chloroacetanilide class) which are listed in Iranian national standard (ISIRI 1053 of Iran) [17] as the most commonly used local agricultural pesticides are selected. A sufficiently reliable and sensitive HPLC method with SPE preconcentration and clean-up step for the determination of selected pesticides with different organic class was presented for environmental waters and particularly drinking water samples. The main parameters for validating an analytical methodology include assays of linearity, precision, and detection limit. Also this method was applied for determinations of these components in Tehran's drinking water outlet of water treatment plant number $\mathbf{1}$, number $\mathbf{2}$, number $\mathbf{3}$ and $\mathbf{4}$, number $\mathbf{5}$ and number 7. Also the results compared with ISIRI 1053, world health organization (WHO) [18] and the United States Environmental Protection Agency's (EPA) guidelines [19].

\section{Experimental}

\subsection{Chemicals and reagents}

Standards of Simazine and Atrazine from Fulka and Chlorotoluron, Isoproturon and
Metolachlor from Sigma-Aldrich were purchased. The ultra-pure water was prepared by Milli- ${ }^{\circledR}$ water purification system. HPLC grade methanol and acetonitrile were purchased from Merck. Waters Sep-Pak C-18 cartridge was also used. A stock standard solution containing $50 \mathrm{mg} \mathrm{L}^{-1}$ of pesticides was prepared in HPLC grade methanol. The stock solution was stored at $-20{ }^{\circ} \mathrm{C}$. Working standard solutions were daily prepared by diluting the stock standard solution with ultra-pure water to the required concentrations. Drinking water samples were collected from the water treatment plants of Tehran. No filtration or any further treatment was applied in any of the samples before extraction.

\subsection{Apparatus}

Chromatographic analysis was performed with a HPLC system including a Knauer K1001 HPLC pump, a four-port Cheminert HPLC valve from Knauer with a $20 \mu \mathrm{L}$ sample loop and equipped with a Knauer K2600 UV-Vis detector. Chromatographic data were recorded and analyzed using EZChrom software (version 3.1.7). AC18 column $(250 \mathrm{~mm} \times 4.6 \mathrm{~mm}$, with $3 \mu \mathrm{m}$ particle size) and aC18 guard column (3.9 $m m \times 20 m m$ ) were applied to separate the pesticides under gradient elution conditions. A mixture of ultra-pure water 
and acetonitrile as a mobile phase with $65: 35$ ratio was changed to $98: 2$ ratioin 20 min gradient time at a flow rate 1.5 mLmin- $^{-}$ 1 and the analytes were detected at $280 \mathrm{~nm}$.

\subsection{Extraction and analysis}

The target compounds were extracted from water samples using the SPE cartridge. For the recovery test and measurement uncertainties, the pesticides were spiked (in triplicate) in $100 \mathrm{~mL}$ of ultra-pure water. First, we had conditioning the cartridge with $2 \times 2 \mathrm{~mL}$ of methanol and $2 \times 2 \mathrm{~mL}$ of Milli-Q water; then loading $100 \mathrm{~mL}$ of sample water at $1 \mathrm{~mL} / \mathrm{min}$ rate and finally the elution step including $5 \mathrm{~mL}$ of methanol in a $15 \mathrm{~mL}$ PP tube and, then, $20 \mu \mathrm{L}$ was injected to HPLC system.

\section{Results and discussion}

The analytical performance of the proposed SPE method under optimum conditions was validated through the determination of preconcentration factors (PFs), limit of detections (LODs), linear dynamic ranges (LDRs), and precision (RSDs) for the pesticides (Table 1). The curves were obtained by injecting extracts of the pesticides with variable concentrations of the pesticides $\left(0-1000 \mu \mathrm{g} . \mathrm{L}^{-1}\right)$. HPLC chromatogram of a standard mixture of 5 pesticides obtained from $100 \mu \mathrm{g} . \mathrm{L}^{-1}$ level is shown in Figure 1. To evaluate the linearity of the method, a series of solutions at fifteen different concentrations (ranging from 0.005 to $1000 \mu \mathrm{g} . \mathrm{L}^{-1}$ ) were prepared by spiking ultra-pure water with five pesticides. The results were summarized in Table 1. Linearity was observed over the range of $0.005-1000,0.01-1000,4-1000$, 10.5-1000 and 9.48-1000 $\mu \mathrm{g} . \mathrm{L}^{-1}$ for Simazine, Atrazine, Isoproturon, Metolachlor and Chlorotoluron respectively with correlations of determinations more than 0.991. LOD for each pesticides, based on a signal to noise ratio $(\mathrm{S} / \mathrm{N})$ of 3 , was $0.001,0.003,1.19,3.16$ and $2.184 \mu \mathrm{g} . \mathrm{L}^{-1}$ for Simazine, Atrazine, Isoproturon, Metolachlor and Chlorotoluron respectively. The within-day precisions ranged from 4.8 to $6.7 \%$ and the between-day precisions ranged of 7.8-13.3\% based on the peak areas for five replicates. The PFs were varied between 15.04-22.53.

This method was successfully applied for determinations of these components in Tehran's drinking water outlet of water treatment plant number 1, number 2, number 3 and 4 , number 5 and number 7 . All samples had no pesticides higher than LOD value.The concentration of all pesticides was lower than the guideline value proposed by WHO as well as that of Iranian National Drinking Water Standards (ISIRI 10503) for all of the samples. Comparison of pesticide concentrations in outlet of water treatment plants showed that there existed significant 
similarity between them (no of them had pesticides). In Tehran Water Treatment Plant, conventional treatment operations were performed for producing drinking water which included coagulation, flocculation, sedimentation, sand filtration, and disinfections [20]. Consequently, the conventional water treatment processes were efficient for the removal of pesticides from drinking water supplies.

Table 1. Figures of merit for SPE of pesticides

\begin{tabular}{|c|c|c|c|c|c|c|c|}
\hline \multirow[t]{2}{*}{ Analyte } & \multirow{2}{*}{$\begin{array}{c}\text { Retention } \\
\text { time } \\
\text { (min) }\end{array}$} & \multicolumn{2}{|c|}{ Linearity } & \multirow[t]{2}{*}{$\begin{array}{c}\text { LOD } \\
\left(\mu \mathrm{g} . \mathrm{L}^{-1}\right)\end{array}$} & \multicolumn{2}{|c|}{$\begin{array}{c}\text { Precision a } \\
(\text { RSD\%, n=5) }\end{array}$} & \multirow[t]{2}{*}{$\mathbf{R F}$} \\
\hline & & LRD ( $\left(\mu g . L^{-1}\right)$ & $\mathbf{R}^{2}$ & & $\begin{array}{c}\text { Between } \\
\text { day }\end{array}$ & $\begin{array}{l}\text { Within- } \\
\text { day }\end{array}$ & \\
\hline Simazine & 6.203 & $0.005-1000$ & 0.9969 & 0.001 & 4.8 & 8.5 & 20.56 \\
\hline Atrazine & 8.460 & $0.010-1000$ & 0.9964 & 0.003 & 5.1 & 7.8 & 22.53 \\
\hline Isoproturon & 9.300 & $4.000-1000$ & 0.9979 & 1.197 & 6.7 & 11.9 & 20.21 \\
\hline Metolachlor & 13.243 & $10.500-1000$ & 0.9930 & 3.165 & 4.9 & 13.3 & 19.75 \\
\hline Chlorotoluron & 17.573 & $9.480-1000$ & 0.9914 & 2.846 & 5.7 & 12.4 & 15.04 \\
\hline
\end{tabular}

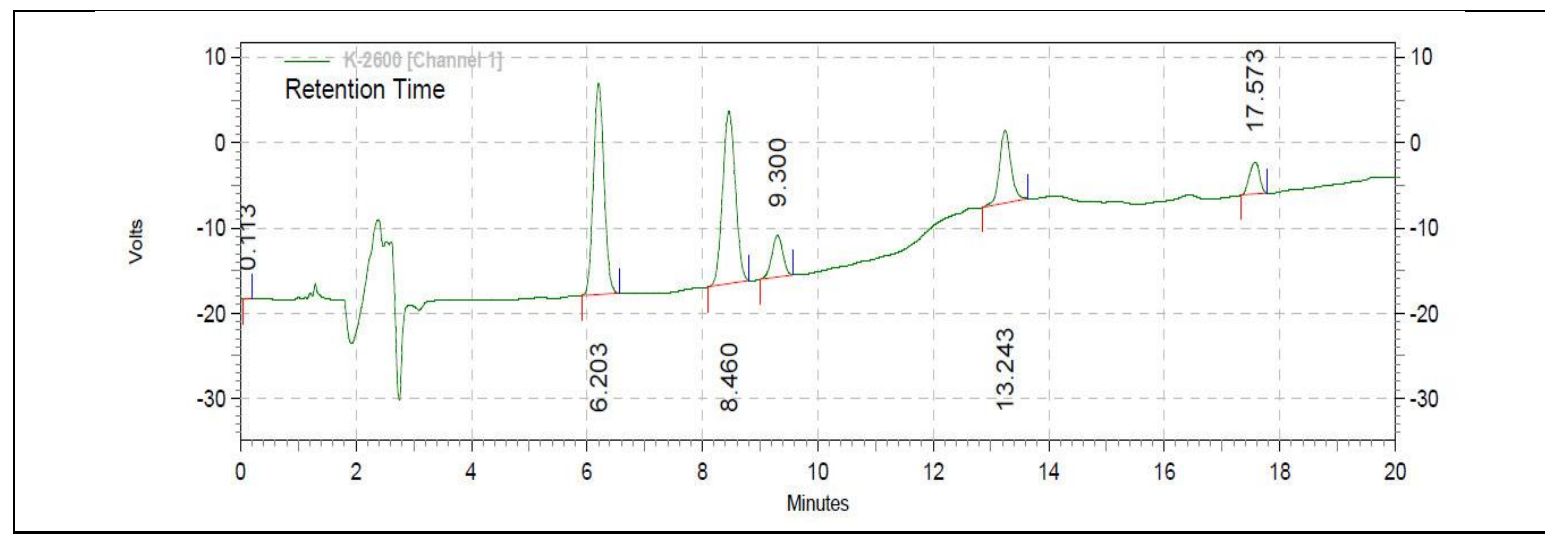

Figure 1: Chromatogram of mix pesticides (50 ppb): Simazine (6.203 min), Atrazine (8.460 min), Isoproturon (9.300 $\mathrm{min}$ ), Metolachlor (12.243 min) and Chlorotoluron (17.573 min)

\section{Conclusion}

In the present study, SPE was used as a sample preparation step before determination of pesticides in drinking water samples by HPLC-UV. The experimental results revealed that this method provided high recovery and preconcentration factor within a short time and good linearity over the investigated concentration range. The performance of this procedure in the extraction of pesticides from treated waters was also satisfactory. The LODs of target pesticides showed a high sensitivity of the proposed method. In addition, the concentration of pesticides in the drinking water was lower than those recommended by ISIRI 1053 which indicated that the water treatment processes in Tehran plants were efficient for 
the removal of pesticides from drinking water supplies.

\section{Acknowledgments}

The authors appreciate the guidance given by Dr. Jalal Hassan in the validation of the test method.

\section{References}

[1]. N. Sankararamakrishnan, A. Kumar Sharma, R. Sanghi, Environ. Int., 2005, 31, 113-120.

[2]. A. Masia, M. Ibanez, C. Blasco, J.V. Sancho, Y. Pico, F. Hernández, Anal. Chim. Acta, 2013, 761, 117-127.

[3]. M.J. Hedegaard, H.J. Albrechtsen, Water Res., 2014, 48, 71-81.

[4]. P.V. Toan, Z. Sebesvari, M. Blasing, I. Rosendahl, F.G. Renaud, Sci. Total Environ., 2013, 452-453, 28-39.

[5]. M.A. Bannwarth, C. Grovermann, P. Schreinemachers, J. Ingwersen, M. Lamers, T. Berger, T. Streck, J. Environ. Manage., 2015, 165, 298-312.

[6]. L.M. Varca, Agric. Water Manag., 2012, 106, 35-41.

[7]. B.M. Teklu, P.I. Adriaanse, M.M.S. Ter Horst, J.W. Deneer, P.J. Van den Brink, Sci. Total Environ., 2015, 508, 566-574.

[8]. S. Mekonen, R. Argaw, A. Simanesew, M. Houbraken, D. Senaeve, A. Ambelu, P. Spanoghe, Chemosphere, 2016, 162, 252260.
[9]. G. Aslan-Sungur, E.O. Gaga, S. YenisoyKarakas, J. Chromatogr. A., 2014, 1325, 4048.

[10]. H. Liu, W. Kong, Y. Qi, B. Gong, Q. Miao, J. Wei, M. Yang, Chemosphere, 2014, 95, 3340.

[11]. M.V. Russo, L. Notardonato, G. Cinelli, P. Avino, Anal. Bioanal. Chem., 2012, 402, 1373-1381.

[12]. E.A. Orlando, A.V. Simionato, J. Chromatogr. A., 2013, 1307, 111-118.

[13]. E. Watanabe, Y. Kobara, K. Baba, H. Eun, Food. Chem., 2014, 154, 7-12.

[14]. E. Passeport, A. Guenne, T. Culhaoglu, S. Moreau, J.M. Bouye, J. Tournebize, J. Chromatogr. A., 2010, 1217, 5317-5327.

[15]. T.G. Schwanz, M. Llorca, M. Farre, D. Barcelo, Sci. Total. Environ., 2016, 539, 143152.

[16]. M. Moradi, Y. Yamini, A. Esrafili, S. Seidi, Talanta, 2010, 82, 1864-1869.

[17]. ISIRI 1053, $5^{\text {th }}$.revision, Institute of Standards and Industrial Research of Iran. Drinking water -Physical and chemical specifications 2010.

[18]. WHO: Guidelines for Drinking-water Quality. $4^{\text {th }}$ edition. World Health Organization; 2011.

[19]. European Communities: The quality of water intended for human consumption. Official Journal of the European Communities Council Directive 98/83/EC. 
[20]. P.E. Stackelberg, J. Gibs, E.T. Furlong,

M.T. Meyer, S.D. Zaugg, R.L. Lippincott, Sci

Total. Environ., 2007, 377, 255-272.

How to cite this manuscript: Mahtab Baghban, Alireza Rezaian, Elaheh Hashemi*, Simultaneous Identification and Determination of Three Different Classes of Pesticides in Tehran Drinking Water by HPLC/UV Technique, Adv. J. Chem. A, 2018, 1(2), 110-166.

85 2018, 1(2), 79-85| http://ajchem-a.com 